\section{BMJ Open} Ophthalmology

\title{
360-degree suture trabeculotomy ab interno with phacoemulsification in open-angle glaucoma and coexisting cataract: a pilot study
}

\author{
Tomoki Sato, ${ }^{1}$ Takahiro Kawaji, ${ }^{1}$ Akira Hirata, ${ }^{2}$ Takanori Mizoguchi ${ }^{3}$
}

To cite: Sato T, Kawaji T, Hirata A, et al. 360-degree suture trabeculotomy ab interno with phacoemulsification in open-angle glaucoma and coexisting cataract: a pilot study. BMJ Open Ophthalmology 2018;3:e000159. doi:10.1136/ bmjophth-2018-000159

Received 24 February 2018 Revised 27 July 2018 Accepted 30 September 2018

Check for updates

(c) Author(s) (or their employer(s)) 2018. Re-use permitted under CC BY-NC. No commercial re-use. See rights and permissions. Published by BMJ.

${ }^{1}$ Sato Eye and Internal Medicine Clinic, Kumamoto, Japan

${ }^{2}$ Hayashi Eye Hospital, Fukuoka, Japan

${ }^{3}$ Mizoguchi Eye Clinic, Nagasaki, Japan

Correspondence to Takahiro Kawaji; kawag@white. plala.or.jp

\section{ABSTRACT}

Objective We performed a pilot trial to evaluate the 24-month safety and efficacy of 360-degree suture trabeculotomy ab interno with phacoemulsification used to treat mild to moderate open-angle glaucoma coexisting with cataract.

Methods and analysis We randomly assigned 18 eyes with open-angle glaucoma and coexisting cataract to undergo 360-degree suture trabeculotomy ab interno with phacoemulsification (combined) or phacoemulsification alone (control) (1:1 ratio) and followed up patients for 24 months. Main outcome measures were mean postoperative intraocular pressure (IOP) and success probabilities based on Kaplan-Meier life table analyses. Surgical success was defined as follows: criterion A: IOP value $\geq 6 \mathrm{~mm} \mathrm{Hg}$ and $\leq 15 \mathrm{~mm} \mathrm{Hg}$, with $\geq 20 \%$ reduction without medication; criterion $\mathrm{B}$ : IOP value $\geq 6 \mathrm{~mm} \mathrm{Hg}$ and $\leq 12 \mathrm{~mm} \mathrm{Hg}$, with $\geq 30 \%$ reduction without medication. Secondary outcome measures included the number of medications, complications and best-corrected visual acuity.

Results Mean IOP values (number of medications), which were $18.4 \mathrm{~mm} \mathrm{Hg} \mathrm{(0.9)} \mathrm{and} 17.1 \mathrm{~mm} \mathrm{Hg} \mathrm{(1.3)} \mathrm{at} \mathrm{baseline,}$ showed significant reductions to $11.8 \mathrm{~mm} \mathrm{Hg} \mathrm{(1.0)} \mathrm{and}$ $14.6 \mathrm{~mm} \mathrm{Hg}$ (1.5) at 24 months postoperatively in the combined and control groups, respectively $(p=0.0003$ and 0.0192 , respectively). Success rates for criterion $A$ in the combined and control groups were $77.8 \%$ and $11.1 \%$, respectively $(p=0.0110)$ and those for criterion $B$ in the combined and control groups were $46.7 \%$ and $0 \%$, respectively $(p=0.0036)$. Both groups had a similar overall occurrence of postoperative complications.

Conclusion Using 360-degree suture trabeculotomy ab interno with phacoemulsification appeared to be a more beneficial option for mild to moderate open-angle glaucoma with coexisting cataract than phacoemulsification alone.

Trial registration number UMIN000021170, date of registration: 2016/03/01.

\section{INTRODUCTION}

Glaucoma is a progressive disease that may lead to irreversible ganglion cell damage, which would result in vision impairment or loss. Glaucoma is the second leading cause of irreversible blindness throughout the world,

\section{Significance of the study}

What is already known about this subject?

Microinvasive glaucoma surgery (MIGS) procedures have recently emerged as low-risk surgical methods for open-angle glaucoma, and several studies have demonstrated that MIGS with phacoemulsification appeared to be more effective than phacoemulsification alone in reducing intraocular pressure (IOP) and the number of glaucoma medications required. However, the benefit of 360-degree suture trabeculotomy ab interno, which is a type of MIGS, was not yet confirmed.

\section{What are the new findings?}

We demonstrated, in a pilot trial, that 360-degree suture trabeculotomy ab interno with phacoemulsification for mild to moderate open-angle glaucoma and coexisting cataract was significantly better at achieving the target IOP without medication compared with phacoemulsification alone.

\section{How might these results change the focus of research or clinical practice? \\ Adding a type of MIGS, such as 360-degree suture trabeculotomy ab interno, at the time of phacoemul- sification appeared to benefit treatment of open-an- gle glaucoma with coexisting cataract.}

including Japan. ${ }^{12}$ The only known approach to reducing the risk of visual loss secondary to glaucoma is lowering the intraocular pressure $(\mathrm{IOP})^{3}$ by using topical antiglaucomatous medications, ${ }^{4}$ laser trabeculoplasty ${ }^{5}$ or incisional glaucoma surgery. ${ }^{6}$

The estimated prevalence of primary openangle glaucoma (POAG) in Japan is $3.9 \%$, with a prevalence of $7.5 \%$ in populations older than 70 years of age. ${ }^{7}$ Therefore, a potentially large group of patients exists who require treatments for both glaucoma and coexisting cataract. Phacoemulsification is usually performed when patients with glaucoma and coexisting cataract require cataract surgery. Patients with POAG who undergo phacoemulsification alone are well known to 
demonstrate small reductions in IOP and the number of glaucoma medications required. ${ }^{8}$ Recently, microinvasive glaucoma surgery (MIGS) procedures that do not require incisions of the conjunctiva and the sclera, such as those using the Trabectome (NeoMedix, Tustin, California, USA) or iStent (Glaukos, Laguna Hills, California, USA), have emerged as low-risk surgical methods for POAG because they are minimally traumatic and very adaptable. ${ }^{9-11}$ Several studies demonstrated that MIGS with phacoemulsification was significantly more effective than phacoemulsification alone in reducing IOP levels and the number of glaucoma medications required. ${ }^{9-12}$

In a previous study, we investigated 360-degree suture trabeculotomy ab interno, which is a type of MIGS, and found that a 360-degree Schlemm canal incision with a 5-0 nylon suture reduced IOP values. ${ }^{13}$ When we used this procedure in patients with POAG or exfoliation glaucoma (XFG), the mean IOP decreased significantly from $19.4 \mathrm{~mm} \mathrm{Hg}$ preoperatively to $13.8 \mathrm{~mm} \mathrm{Hg}$ at 6 months after surgery (28.9\% decrease from preoperative IOP). In addition, the mean number of medications decreased from 3.2 to 1.1. Thus, as for other MIGS, 360-degree suture trabeculotomy ab interno with phacoemulsification for open-angle glaucoma and coexisting cataract may be more effective than phacoemulsification alone. However, this possibility has yet to be confirmed.

In an effort to confirm this result, we conducted a pilot study to evaluate the efficacy and safety of 360-degree suture trabeculotomy ab interno with phacoemulsification for mild to moderate open-angle glaucoma and coexisting cataract and to compare this combined approach with phacoemulsification alone.

\section{MATERIALS AND METHODS}

\section{Study design}

This prospective, randomised, open-label, single-centre clinical trial was conducted at the Sato Eye and Internal Medicine Clinic (Arao City, Kumamoto, Japan) between October 2014 and April 2015. Via a random numbers table, we randomly assigned patients to one of the two treatment groups: 360-degree suture trabeculotomy ab interno with phacoemulsification (combined group) or phacoemulsification alone (control group). Given that this was a pilot study, sample size estimation was not performed. This report describes the second year of follow-up for all randomised patients. The study protocol adhered to the tenets of the Declaration of Helsinki and was registered with the University Hospital Medical Information Network (UMIN) Clinical Trials Registry of Japan with the registration number UMIN000021170. Before surgery, informed written consent was obtained from all patients.

\section{Patient population}

After Institutional Review Board approval, all patients provided written informed consent. To be included in the study, patients had to be diagnosed with mild to moderate POAG including normal-tension glaucoma or XFG with coexisting cataract and require phacoemulsification. Mild to moderate glaucoma was defined as visual field defects consistent with optic nerve abnormalities and a cup-to-disc ratio not worse than 0.8 , plus a medicated IOP of $24 \mathrm{~mm} \mathrm{Hg}$ or lower when using 1-3 medications. Cataract was clinically defined as cataract with the presence of glare or halo, with a best-corrected visual acuity (BCVA) of $\leq 20 / 20$. POAG was defined as optic neuropathy with open angle (Shaffer grade 3 or 4 ), with typical matching disc and field changes. Normal-tension glaucoma was defined as glaucomatous optic neuropathy with open angle and matching visual field loss in the presence of an IOP value of $\leq 21 \mathrm{~mm} \mathrm{Hg}$. XFG was diagnosed on the basis of exfoliation materials adhering to the lens surface or to the iris pupillary margin and a wide-open angle with dense pigmentation, Sampaolesi's line, and an optic neuropathy matching visual field loss.

Patients were excluded if they had neovascular, uveitic or angle recession glaucoma; had previous glaucoma, vitrectomy, buckling surgery or refractive surgery; were known to be corticosteroid responders; had severely uncontrolled IOP or severe glaucomatous field defects or had ocular disease that would affect safety or interfere with the tests. Patients who met the inclusion criteria were consecutively enrolled in the study. All procedures were performed by one surgeon (TS) who used the surgical procedure described herein. Only one eye from each patient was included in this study. If a patient underwent bilateral surgery, only the first eye operated on was analysed.

\section{Surgical technique}

360-degree suture trabeculotomy ab interno with phacoemulsification

During the first step, a 360-degree suture trabeculotomy ab interno was performed according to a previously described method. ${ }^{13}$ After a $1.7 \mathrm{~mm}$ temporal corneal incision was made, Schlemm's canal was incised 15 degrees on the nasal side by using the Trabectome. Next, the rounded tip of a 5-0 nylon suture was inserted into Schlemm's canal by using a 23-gauge disposable glass forceps (DSP forceps, Alcon, Tokyo, Japan). After the suture tip was passed around the circumference of Schlemm's canal, it was pulled out from the same opening, with the forceps used to perform a 360-degree incision of Schlemm's canal. Phacoemulsification was then performed by means of a separate incision.

\section{Phacoemulsification}

A $2.4 \mathrm{~mm}$ clear corneal incision was made in the superotemporal meridian. After a capsulorhexis was created, phacoemulsification was performed and a foldable acrylic intraocular lens was implanted by using an injector. A balanced salt solution was then injected through the side-port incision to inflate the anterior chamber. The integrity of the wound was assessed by closely checking for wound leakage. 
Table 1 Demographical and clinical characteristics of the patients

\begin{tabular}{llll}
\hline Variable & $\begin{array}{l}\text { Combined group } \\
(\mathbf{n = 9})\end{array}$ & $\begin{array}{l}\text { Control group } \\
(\mathbf{n = 9})\end{array}$ & P values \\
\hline Male/female, $\mathrm{n} / \mathrm{n}$ & $5 / 4$ & $3 / 6$ & 0.6372 \\
\hline Age (years) & $74.2 \pm 9.5$ & $74.4 \pm 3.6$ & 1.0000 \\
\hline Glaucoma subtypes (POAG/XFG), $\mathrm{n} / \mathrm{n}$ & $6 / 3$ & $8 / 1$ & 0.5765 \\
\hline Right eye/left eye, $\mathrm{n} / \mathrm{n}$ & $6 / 3$ & $5 / 4$ & 1.0000 \\
\hline Preoperative intraocular pressure (mm Hg) & $18.4 \pm 3.6$ & $17.1 \pm 4.5$ & 0.4795 \\
\hline Medications & $0.9 \pm 1.4$ & $1.3 \pm 1.3$ & 0.3992 \\
\hline Best-corrected visual acuity (logMAR) & $0.24 \pm 0.25$ & $0.88 \pm 0.69$ & 0.0209 \\
\hline Visual field (MD, dB) & $-5.8 \pm 3.3$ & $-6.1 \pm 3.5$ & 0.9233 \\
\hline Corneal endothelial cell density (/mm $\left.{ }^{2}\right)$ & $2624 \pm 224$ & $2682 \pm 100$ & 0.5961 \\
\hline Follow-up period (months) & $19.3 \pm 7.2$ & $22.7 \pm 4.0$ & 0.2476 \\
\hline
\end{tabular}

Continuous data are expressed as means \pm SD.

logMAR, logarithm of minimum angle of resolution; MD, mean deviation; POAG, primary open-angle glaucoma; XFG, exfoliation glaucoma.

\section{Examinations}

All patients underwent slit-lamp biomicroscopy, indirect ophthalmoscopy, manifest refraction, measurement of IOP and determination of BCVA via a conventional Landolt ring chart. For the analyses, we converted the visual acuities (decimals) into the logarithm of the minimum angle of resolution (logMAR) units. After we discontinued all patients' previous medications for at least 1 month, we obtained three separate IOP measurements within 1 month of surgery; we used the average of the measurements as the IOP baseline. We examined the patients at 1, 2 and 3 days after surgery, and then 1-2 weeks thereafter for 1 month, every month until 6 months and every 2 or 3 months until 24 months. During this follow-up period, we measured the IOP at every visit. As per study protocol, medications were added when the IOP exceeded $21 \mathrm{~mm} \mathrm{Hg}$ after 2 weeks postoperatively, when it exceeded $15 \mathrm{~mm} \mathrm{Hg}$ after 1 month postoperatively, or when it was necessary to treat visual field or optic nerve findings.

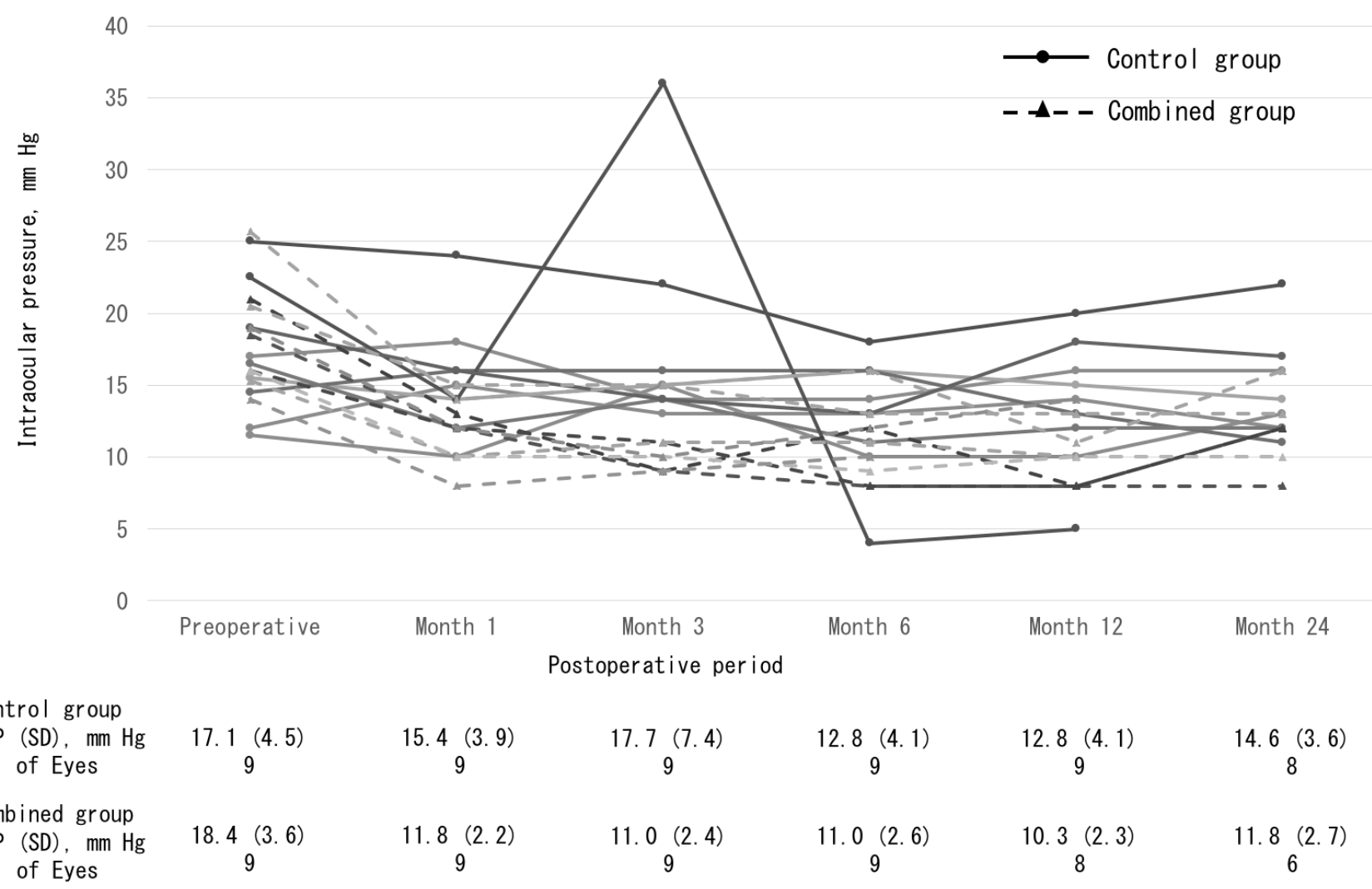

Figure 1 Time course of intraocular pressure (IOP) in eyes with combined group and control group. 

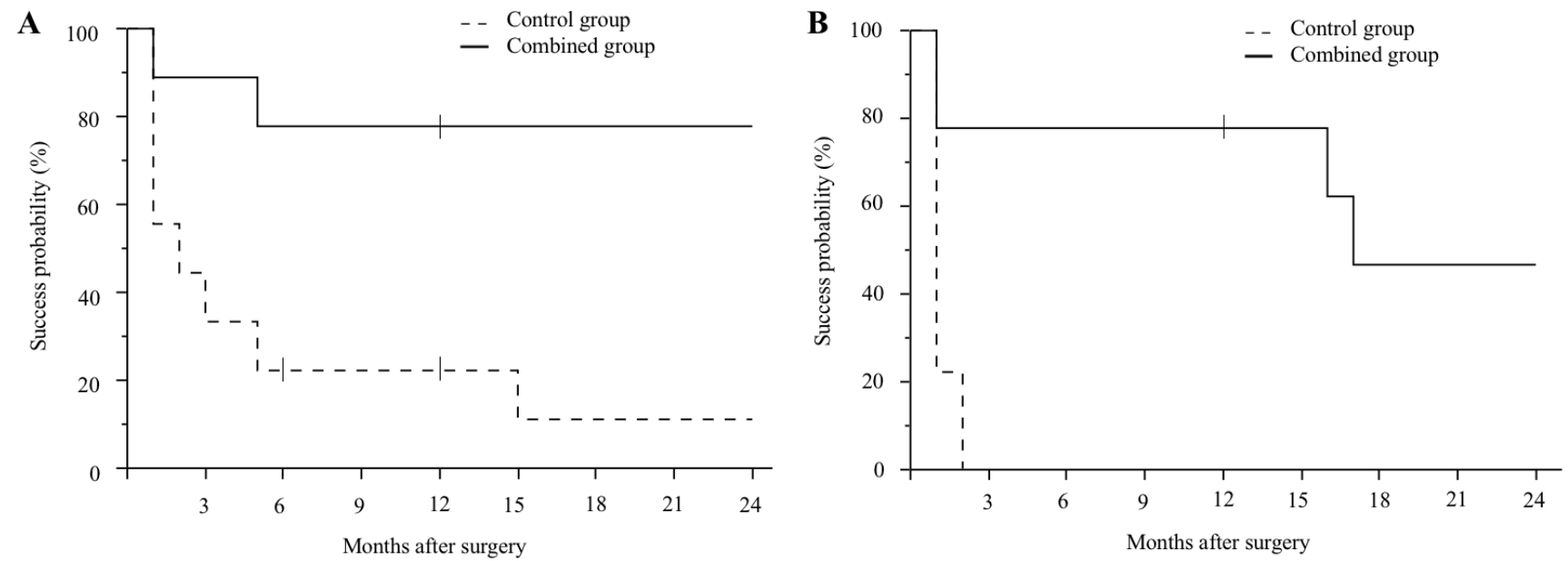

Figure 2 (A) Kaplan-Meier survival curves for success criterion A (an intraocular pressure (IOP) value of $\geq 6 \mathrm{~mm} \mathrm{Hg}$ and $\leq 15$ $\mathrm{mm} \mathrm{Hg}$ and postoperative reduction in IOP value of $\geq 20 \%$ without medication during the follow-up period). (B) Kaplan-Meier survival curves for success criterion B (an intraocular pressure (IOP) value of $\geq 6 \mathrm{~mm} \mathrm{Hg}$ and $\leq 12 \mathrm{~mm}$ Hg and postoperative reduction in IOP value of $\geq 30 \%$ without medication during the follow-up period). The small vertical dash along the curves represents the time of censored observation.

\section{Outcome measures}

Efficacy

Main outcome measures included the continuous analysis of IOP and the cumulative success rate of patients according to Kaplan-Meier life table analysis. Surgical success was defined as (1) an IOP value of $\geq 6 \mathrm{~mm} \mathrm{Hg}$ and $\leq 15 \mathrm{~mm} \mathrm{Hg}$ and a postoperative reduction in IOP of $\geq 20 \%$ without medication (criterion A) and as (2) an IOP value of $\geq 6 \mathrm{~mm} \mathrm{Hg}$ and $\leq 12 \mathrm{~mm} \mathrm{Hg}$ and a postoperative reduction in IOP of $\geq 30 \%$ without medication (criterion B). Cases were considered to be failures if the success criteria were not met at two consecutive visits after the first postoperative month, or if additional glaucoma surgery was needed. The secondary outcome measure was the continuous analysis of the number of medications required.

\section{Safety}

Safety factors included complications either during or after surgery and BCVA. In terms of postoperative complications, an IOP value of $\geq 30 \mathrm{~mm} \mathrm{Hg}$ within 1 month after the original surgery and a day-to-day increase in the IOP value of $\geq 5 \mathrm{~mm} \mathrm{Hg}$ were defined as IOP spikes. Hypotony was defined as an IOP value of $\leq 5 \mathrm{~mm} \mathrm{Hg}$.

\section{Statistical analyses}

JMP V.12 (SAS Institute, Cary, North Carolina, USA) was used for data analysis. Because of the small sample size in this study, continuous variables were expressed as means \pm SD and were then analysed by using the MannWhitney non-parametric test with Bonferroni correction. Categorical variables were compared by using Fisher's exact test analysis. Differences between subgroups in Kaplan-Meier life table analyses were evaluated by using the log-rank test. The statistical significance level was set at $\mathrm{p}<0.05$.

\section{RESULTS}

\section{Enrollment and disposition}

Of 24 patients with open-angle glaucoma and coexisting cataract who required phacoemulsification between October 2014 and April 2015, six were excluded for the following reasons: two patients had a history of glaucoma surgery; three had severe glaucoma and one did not sign the consent form for the study. All remaining 18 patients were randomly assigned to either the combined group or the control group and underwent the procedure as planned. Although one patient in the control group required additional filtering surgery at 5 months after surgery, all follow-up measurements were included in the calculations. Seventeen (94\%) patients completed the 12-month postoperative visit and $14(78 \%)$ patients attended the 24-month postoperative visit. Three patients in the combined group and one patient in the control group missed the 24-month postoperative visit because of poor health .

\section{Prestudy characteristics}

Table 1 summarises the demographic characteristics of all patients before surgery. No significant difference was seen between the two groups except for BCVA.

\section{Outcomes}

Efficacy

\section{Main outcomes}

As figure 1 shows, the mean IOP in the combined group was significantly reduced from $18.4 \pm 3.6$ (14-26) $\mathrm{mm} \mathrm{Hg}$ preoperatively to $11.8 \pm 2.7(8-14) \mathrm{mm} \mathrm{Hg}$ at 24 months 
$\mathrm{mmHg}$

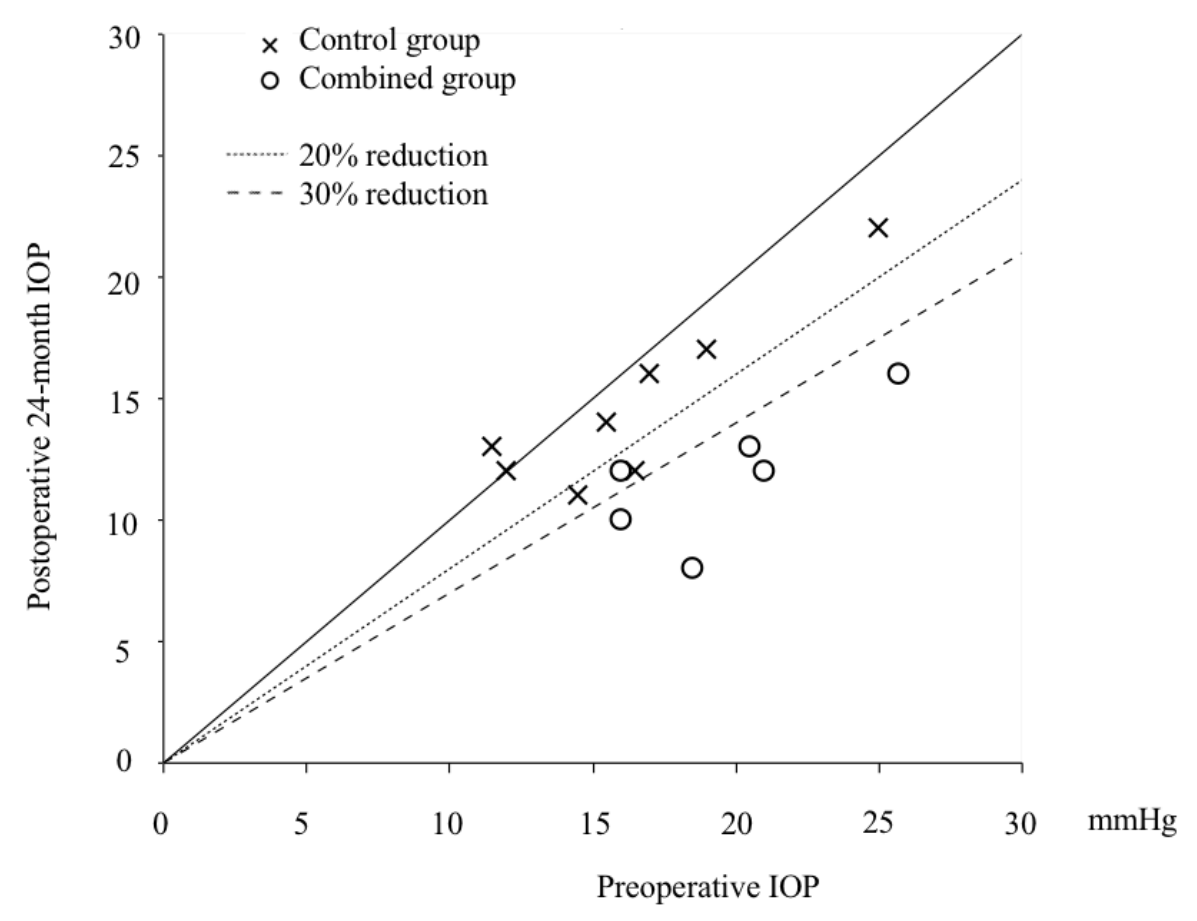

Figure 3 Preoperative and postoperative 24-month intraocular pressure (IOP) with sloped lines of $20 \%$ or $30 \%$ reduction from the IOP baseline.

after surgery $(35.9 \%$ reduction; $\mathrm{p}=0.0003)$, with the mean number of $1.0 \pm 1.7$ medications used at 24 months after surgery. In the control group, the mean IOP was significantly reduced from $17.1 \pm 4.5(12-25) \mathrm{mm} \mathrm{Hg}$ preoperatively to $14.6 \pm 3.6(10-20) \mathrm{mm} \mathrm{Hg}$ at 24 months after surgery $(14.6 \%$ reduction; $\mathrm{p}=0.0192)$, with the mean number of $1.2 \pm 1.4$ medications used at 24 months after surgery. No significant differences in IOP between the groups were found at each time point after surgery.

Figure 2 presents the Kaplan-Meier cumulative survival analyses over time, which showed that the success rates of the combined group were significantly higher than those of the control group for both criteria. At 24 months after surgery, the success rate for criterion A was $77.8 \%$ in the combined group and $11.1 \%$ in the control group ( $\mathrm{p}=0.0110$ (log-rank test)). For criterion B, the success rates were $46.7 \%$ in the combined group and $0 \%$ in the control group $(\mathrm{p}=0.0036$ (log-rank test)). Figure 3 also shows a scattergram of preoperative and postoperative 24-month IOP with sloped lines of $20 \%$ or $30 \%$ reduction from the IOP baseline.

\section{Secondary outcomes}

The preoperative and postoperative 24 month mean numbers of medications were $0.9 \pm 1.4$ and $1.0 \pm 1.7$ in the combined group and $1.3 \pm 1.3$ and $1.5 \pm 1.4$ in the control group, respectively. No significant difference was noted between the two groups during any follow-up period.

\section{Safety}

Table 2 indicates that no severe intraoperative or postoperative complications occurred. The most frequent postoperative complications included hyphema in the combined surgery group and IOP spikes in both groups. Intraoperative reflux bleeding occurred in all eyes in the combined surgery group, with hyphema occurring in two (22\%) eyes 1 day postoperatively. However, all eyes had spontaneous resolution within 1 week. In both groups, three $(36 \%)$ eyes exhibited IOP spikes. IOP values of $<30 \mathrm{~mm} \mathrm{Hg}$ were achieved by using temporary systemic carbonic anhydrase inhibitors within 3 days in all eyes. No postoperative hypotony was observed. The rate of corneal endothelial cell density decrease at 24 months after surgery was $5.7 \% \pm 3.4 \%$ in the combined group and $6.1 \% \pm 5.9 \%$ in the control group. Because of uncontrolled IOP while medications were being used, one eye in the control group required additional filtering surgery at 5 months after the initial surgery. After surgery, the IOP was reduced to $<10 \mathrm{~mm} \mathrm{Hg}$ without medication. The BCVAs at 24 months after surgery were $0.07 \pm 0.09$ in the combined group and $0.12 \pm 0.11$ in the control group. All eyes in both groups showed improvement from baseline BCVA.

\section{DISCUSSION}

In this study, which was a pilot trial, we evaluated the efficacy and safety of 360-degree suture trabeculotomy ab 
Table 2 Complications

\begin{tabular}{|c|c|c|c|}
\hline \multirow[b]{2}{*}{ Complications } & Combined group & Control group & \multirow[b]{2}{*}{$P$ values } \\
\hline & $(n=9)$ & $(n=9)$ & \\
\hline \multicolumn{4}{|l|}{ Intraoperative } \\
\hline Reflux bleeding & $9(100)$ & $0(0)$ & $<0.0001^{\star}$ \\
\hline Anterior chamber flattening & $0(0)$ & $0(0)$ & 1.0000 \\
\hline Descemet's detachment & $0(0)$ & $0(0)$ & 1.0000 \\
\hline \multicolumn{4}{|l|}{ Postoperative } \\
\hline Hyphema & $2(22)$ & $0(0)$ & 0.4706 \\
\hline Intraocular pressure spike & $3(33)$ & $3(33)$ & 1.0000 \\
\hline Hypotony & $0(0)$ & $0(0)$ & 1.0000 \\
\hline Rate of endothelial cell loss (\%) & $5.7 \pm 3.4$ & $6.1 \pm 5.9$ & 1.0000 \\
\hline Infection & $0(0)$ & $0(0)$ & 1.0000 \\
\hline $\begin{array}{l}\text { Best-corrected visual acuity decrease by } \geq 2 \\
\text { lines }\end{array}$ & $0(0)$ & $0(0)$ & 1.0000 \\
\hline Additional glaucoma surgery & $0(0)$ & $1(11)$ & 1.0000 \\
\hline
\end{tabular}

Data are presented as $\mathrm{n}(\%)$; continuous data are presented as means \pm SD.

*Statistically significant difference between groups (Fisher's exact test).

interno with phacoemulsification for mild to moderate open-angle glaucoma and coexisting cataract compared with phacoemulsification alone. More eyes that underwent combined surgery significantly achieved the target IOP without medication compared with eyes that underwent phacoemulsification alone. In addition, no serious complications were observed in either group, and the majority of patients in both groups demonstrated similar improvements in 24-month postoperative BCVA.

Incising the 360-degree trabecular meshwork and the inner wall of Schlemm's canal by using the 360-degree suture trabeculotomy ab interno procedure can reduce the 360-degree resistance to fluid flow from the trabecular meshwork to the collector channels. As a result, the aqueous humour can flow directly to the all collector channel ostia and a reduced IOP may be achieved. Several mechanisms for the reduction in IOP after phacoemulsification have been proposed. A postoperative increase in angle width ${ }^{14}$ or traction on the ciliary body via the zonules in pseudophakia ${ }^{15}$ may increase aqueous outflow. Increases in prostaglandin $\mathrm{F}_{2 \alpha_{17}}$ levels, ${ }^{16}$ postoperative blood ocular barrier permeability ${ }^{2 \alpha_{7}}$ or a potentially IOP-lowering stress response induced in trabecular meshwork cells by ultrasound $^{18}$ may lead to lower IOP.

Although the mean baseline IOP values in the present study were not excessively high $(18.4 \pm 3.6 \mathrm{~mm} \mathrm{Hg})$, we found a reduction in the 24-month postoperative IOP to $11.8 \mathrm{~mm} \mathrm{Hg}$ (35.9\% reduction) in the combined group. In normal-tension glaucomatous eyes, a reduction in IOP of $1-2 \mathrm{~mm} \mathrm{Hg}$ is believed to indicate a valuable therapeutic effect. ${ }^{19}$ Our result here therefore suggests that utilising 360-degree suture trabeculotomy ab interno with phacoemulsification for mild to moderate open-angle glaucoma coexisting with cataract may be a beneficial strategy.
The most frequent complications observed after 360-degree suture trabeculotomy ab interno are postoperative hyphema and IOP spikes. In the present study, hyphema and IOP spikes were well controlled for several days by using medication alone. All eyes in both groups demonstrated BCVA improvement. Therefore, from a safety perspective, the addition of the 360-degree suture trabeculotomy ab interno did not produce any additional substantial risk or severe complications.

Limitations of the current study include the small number of patients and the fact that the preoperative IOP was not excessively high in either group. The Tajimi Study from $\operatorname{Japan}^{7}$ reported the prevalence of POAG in patients with an IOP of $\leq 21 \mathrm{~mm} \mathrm{Hg}$ to be $3.6 \%$, which was significantly higher than the $0.3 \%$ for patients with POAG with an IOP $>21 \mathrm{~mm} \mathrm{Hg}$. Therefore, in Japan, many treatments are performed for patients who have POAG but who do not have a high IOP, similar to the situation found in the current study. Given that our study was a pilot study, additional investigations with larger sample sizes and longer follow-up periods are needed to confirm these results.

In conclusion, compared with using phacoemulsification alone, performing 360-degree suture trabeculotomy $\mathrm{ab}$ interno at the time of phacoemulsification may be of benefit by reducing postoperative IOP without the need for medication.

Contributors TS and TK planned the study and collected the data. AH and TM supervised the study. TS and TK wrote the manuscript.

Funding The authors have not declared a specific grant for this research from any funding agency in the public, commercial or not-for-profit sectors.

Competing interests None declared.

Patient consent Obtained. 
Ethics approval Institutional Review Board and the Ethics Committee at Sato Eye and Internal Medicine Clinic.

Provenance and peer review Not commissioned; externally peer reviewed.

Open access This is an open access article distributed in accordance with the Creative Commons Attribution Non Commercial (CC BY-NC 4.0) license, which permits others to distribute, remix, adapt, build upon this work non-commercially, and license their derivative works on different terms, provided the original work is properly cited, appropriate credit is given, any changes made indicated, and the use is non-commercial. See: http://creativecommons.org/licenses/by-nc/4.0

\section{REFERENCES}

1. Quigley HA, Broman AT. The number of people with glaucoma worldwide in 2010 and 2020. Br J Ophthalmol 2006;90:262-7.

2. Iwase A, Araie M, Tomidokoro A, et al. Prevalence and causes of low vision and blindness in a Japanese adult population: the Tajimi Study. Ophthalmology 2006;113:1354-62.

3. Leske MC, Heijl A, Hyman L, et al. Early Manifest Glaucoma Trial: design and baseline data. Ophthalmology 1999:106:2144-53.

4. Kass MA, Heuer DK, Higginbotham EJ, et al. The Ocular Hypertension Treatment Study: a randomized trial determines that topical ocular hypotensive medication delays or prevents the onset of primary open-angle glaucoma. Arch Ophthalmol 2002;120:701-13.

5. The Glaucoma Laser Trial (GLT) and glaucoma laser trial follow-up study: 7. Results. Glaucoma Laser Trial Research Group. Am J Ophthalmol 1995;120:718-31.

6. Lichter PR, Musch DC, Gillespie BW, et al. Interim clinical outcomes in the Collaborative Initial Glaucoma Treatment Study comparing initial treatment randomized to medications or surgery. Ophthalmology 2001;108:1943-53.

7. Iwase A, Suzuki Y, Araie M, et al. The prevalence of primary openangle glaucoma in Japanese: the Tajimi Study. Ophthalmology 2004;111:1641-8.

8. Chen PP, Lin SC, Junk AK, et al. The effect of phacoemulsification on intraocular pressure in glaucoma patients: a report by the american academy of ophthalmology. Ophthalmology 2015;122:1294-307.

9. Shoji N, Kasahara M, lijima A, et al. Short-term evaluation of Trabectome surgery performed on Japanese patients with openangle glaucoma. Jpn J Ophthalmol 2016;60:156-65.

10. Malvankar-Mehta MS, lordanous $\mathrm{Y}$, Chen YN, et al. iStent with phacoemulsification versus phacoemulsification alone for patients with glaucoma and cataract: a meta-analysis. PLoS One 2015;10:e0131770.

11. Saheb H, Ahmed II. Micro-invasive glaucoma surgery: current perspectives and future directions. Curr Opin Ophthalmol 2012;23:96-104.

12. Kaplowitz K, Bussel II, Honkanen R, et al. Review and metaanalysis of ab-interno trabeculectomy outcomes. $\mathrm{Br} \mathrm{J}$ Ophthalmol 2016;100:594-600.

13. Sato T, Hirata A, Mizoguchi T. Prospective, noncomparative, nonrandomized case study of short-term outcomes of $360^{\circ}$ suture trabeculotomy ab interno in patients with open-angle glaucoma. Clin Ophthalmol 2015;9:63-8.

14. Hayashi K, Hayashi $\mathrm{H}$, Nakao F, et al. Changes in anterior chamber angle width and depth after intraocular lens implantation in eyes with glaucoma. Ophthalmology 2000;107:698-703.

15. Shingleton BJ, Pasternack JJ, Hung JW, et al. Three and five year changes in intraocular pressures after clear corneal phacoemulsification in open angle glaucoma patients, glaucoma suspects, and normal patients. J Glaucoma 2006;15:494-8.

16. Kerstetter JR, Brubaker RF, Wilson SE, et al. Prostaglandin F2 alpha1-isopropylester lowers intraocular pressure without decreasing aqueous humor flow. Am J Ophthalmol 1988;105:30-4.

17. Miyake K, Asakura M, Kobayashi $\mathrm{H}$. Effect of intraocular lens fixation on the blood-aqueous barrier. Am J Ophthalmol 1984;98:451-5.

18. Wang N, Chintala SK, Fini ME, et al. Ultrasound activates the TM ELAM-1/IL-1/NF-kappaB response: a potential mechanism for intraocular pressure reduction after phacoemulsification. Invest Ophthalmol Vis Sci 2003;44:1977-81.

19. Tomita G, Araie M, Kitazawa Y, et al. A three-year prospective, randomized and open comparison between latanoprost and timolol in Japanese normal-tension glaucoma patients. Eye 2004;18:984-9. 